\title{
Effect of Learners' Autonomy on Undergraduate Students' Achievement in System of Linear Equations in University of Agriculture, Makurdi Benue State, Nigeria.
}

\author{
Iji,Clement. Onwu. Ph.D, Anyor, Joseph Wuave, (Ph.D) \\ Department of Science Education College of Agricultural and Science Education University of \\ Agriculture,Benue State, Nigeria
}

\begin{abstract}
The study investigated the effect of Autonomous learning using matrix Laboratory (MATLAB) on Integrated Science Education Students of the University of Agriculture, Makurdi. Post-test quasi-experimental control group research design was adopted. Thirty students (16 males \& 14 females) formed the experimental group while 44 (29 males, 15 females) formed the control group. The instrument used was Systems of linear Equations Achievement Test (SLEAT) validated by 3 experts in Mathematics Education. The reliability of SLEMAT was 0.74 using split-half and spearman moment correlation coefficient-r. Two hypotheses were tested using $t$-test at 0.05 level of significance. The results revealed that there was a significance difference in the mean achievement scores of students of the experimental group. However, there was no significant difference in the mean achievement scores of male and female students in the experimental group. It was therefore suggested that students be encouraged to adopt independent mathematics learning strategies rather than depending on what the teacher does in the mathematics classroom.
\end{abstract}

Keywords: Learners' Autonomy; undergraduate; Students' Achievement; Liner Equations

\section{Introduction}

Mathematics curriculum delivery in higher institutions of learning in Nigeria poses a great concern to scientists, technologists and mathematics educators. This is because mathematics is the basis of scientific and technological development which are indices for overall national development of nations of the world (Kulbir, 2006). The concern therefore is how best to structure and implement instructional methods to enable individuals to effectively utilize mathematics skills acquired for individual survival and national development.

Mathematics education, with the development of technology emphasizes the need to move away from teacher centered methods of teaching to discursive practices (Yvette, 2007). The teacher centered approaches to teaching are geared towards preparing students for examinations. However, it is not just passing mathematics examinations or getting high marks that counts. According to Mercer (2000), the teacher centered approaches to teaching and learning work in a rather negative direction to foster merely ritual or procedural knowledge which is embedded in the paraphernalia of the lesson without any grips of what it was really all about. He further emphasized a principled transferable knowledge, understanding the issues as concepts and their relationship to real life situations. This point to the importance of discursive classroom practices for effective utilization of mathematical skills for individual and national development and effective interaction with the wider world (Federal Republic of Nigeria (FRN), 2004). This discursive classroom practices are those that enable students discover facts, understand concepts and procedures, acquire skills and apply them in other related situations independently.

The higher levels of education is the focus of this paper for its role in producing individuals of high level manpower to meet the demands of Nigerians and global economy (FRN, 2004). Mathematics stands out as one of the subjects that help achieve the national goals with its universal application to all facets of life activities.

Considering the significance of the individual's independent functioning towards the progress of the society, FRN (2004) emphasizes the importance of structuring instructional systems to develop the practice of self- learning. Here self learning can be likened to autonomous learning. Autonomous learning therefore refers to individual's independent learning from real life experiences, books, and technologies as computers, calculators, in groups or in the form of learning clubs. This is more so that the students are at Piaget's (1979) formal operational stage of metal development. At this stage, the students are capable of thinking and reasoning in abstract contexts, developing hypothesis and testing them as well as making conclusions. They can also tackle problems independently.

Mathematics education reforms throughout the world emphasizes the need to move away from conventional teaching methods to discursive classroom practices in which students negotiate and justify solutions to problems (Yvetter, 2007). Educational technologists have developed multimedia technologies and 
internet which have become relevant technological tools to encourage autonomous learning. For example elearning is suitable for "distance learning" and the use of computers is necessary for aiding the illustration of phenomena and improve efficiency in the teaching and learning process as well as promoting autonomous learning (Yvan, 2012).He averred that autonomous learning is a process through which individuals control their own learning (Yvan, 2012). This implies that learning starts with the individuals, in this study, students, rather than the teacher control their learning. Autonomous learning does not imply that students are left completely on their own. They are given the opportunities to ask questions for clarification of mathematical concepts and procedures from peers and teachers. It also means that students must be allowed to work at their own pace for time restriction may cause mathematics anxiety (Manko, Barbara, Rens, Petra, Monica and Spiel, 2012). In essence therefore, autonomous learning entails providing opportunities for students to develop, control data, apply strategies or skills, make choices, learn at their own pace, explore and demonstrate independently (Manko, etal, 2012). The study therefore employed Computer Based Instruction (CBI) using MATLAB for autonomous learning to ascertain its effect on students' achievement in system of linear Equations. It was an interactive system which does not adopt dimensioning. The system permits the solution of technically complex problems using matrix and vector formulation. Crowe and Zand, (2000) assert that MATLAB integrates computation, visualization and programming into user friendly environment resulting in the solution of problems expressed in mathematical notations. They further stated that MATLAB is indispensible in mathematics courses such as mathematical analysis, differential equations, and linear algebra. This study have chosen systems of linear equations and determined the effect MATLAB on students' achievement in the chosen mathematics concept.

Research evidences show that learner autonomy can improve students' academic achievement. For example Shaughnessy (1993), Armstrong (1997) and Yushan (2004), all investigated the extent to which mathematics aptitude, attitude, English language proficiency, computer prior knowledge, computer ownership and learning styles contributed to mathematics achievement using MATLAB. They found differences among the variables on mathematics achievement. There was however no gender differences in their results. Also Compell (1994) and Costner (2002) reported that students exposed to computer algebra systems achieved higher than in the conventional method group. In all these researches mentioned, learner autonomy and achievement per se was not emphasized. The researchers sought to fill the gap by carrying out this study specifically using learner autonomy with MATLAB.

Gender is a relevant construct in human achievement and other attributes as self concept. Generally there exists difference in mathematics achievement between male and female students in favour of males (Lauchance \& Mazzocco 2006; Freeman, 2003). However, Blosfield, Hannover, Lenzen, Mueller-Boching, Prenzed (2009) reported the difference in favour of the females. This conflicting results call for continued research in different contexts as in this study.

Achievement in this study implies obtaining a good pass categorized as A (70 and above), B (60-69), C (50-59) and D (45-49). Poor pass is between 40 to 44 , all out of 100. For students to obtain such marks they are expected to demonstrate some of the good knowledge and skills required.

Thus the objectives of this study were:

(1) To determine the effects of learner autonomy on students' achievement in system of linear equations using MATLAB.

(2) To find out which gender will improve more in system of linear equations due to the adoption of MATLAB.

\section{Research Hypotheses}

To facilitate this study the following hypotheses were formulated and tested at 0.05 level of significance.

(1) There is no significant difference between the mean achievement scores of students in the experimental and control groups.

(2) There is no significant difference between the mean achievement scores of male and female students in the experimental group.

\section{Methodology}

The study adopted a post-test quasi experimental design. This was necessary since an intact group was used. The group had experienced the same knowledge of mathematics in their pre-University admission examinations. The study was conducted on Integrated Science Educations Students in the Department of Science Education, University of Agriculture, Makurdi, and Benue State, Nigeria. The area was purposefully chosen for convenience of the researchers as staff of the department. The subject was Integrated Science Education (ISE; 106 - Basic Mathematics II - a second semester course for the programme.)

The sample was made up of all the students of integrated science students for 2010/2011 session. The experimental group comprised 30 (16 males and 14 females) while the control group was made up of 44 (29 males and 15 females). The two groups were arrived at by tossing a coin whose head was for the experimental 
group and tail for the control group. The instrument was the Systems of Linear Equations Mathematics Achievement Test (SLEAT). The test was a 20 item objective test to be completed in $1 \frac{1}{2}$ hours. The instrument was validated by three experts in Mathematics Department and two experts in measurement and evaluation all from University of Agriculture, Makurdi. Its reliability was tested on mathematics and statistics students of the same University were not involved in the study. The splithalf method for establishing reliability was adopted using Pearson Moment correlation coefficient " $\mathrm{r}$ ". This yielded an $\mathrm{r}$ of 0.74 .

The procedure involved in carrying out this research was in three phases which include

(1) The pre-treatment phase: The researchers with the help of the experts in the department's of computer laboratory, arranged computer sets for the subjects, they also helped to de-install other soft-wares leaving the MATLAB software. This was necessary to avoid students diverting to other software programme say, to play games. During the first week, participant reviewed the MATLAB programme in terms of how to login, open a new file (m-file), save the work sheet, and understand MATLAB worksheet and command line demons. Specifically on systems of linear Equations, the MATLAB commands were reviewed. Other processes as data acquisition, modeling, simulation, prototyping, data analysis, exploration and visualization. Others features emphasized were graphic users; interface building and algorithm development. Some systems of linear equations with two variables were trial tested.

(2) Treatment Phase: During the treatment phase which lasted for two weeks, students modeled their own systems of linear equations in two or three variable independently and solve them using MATLAB. The solutions obtained were to be confirmed using paper and pencil solutions applying Cramer's rule. This was to be done three hours on Tuesdays and Thursdays of every week. This was arranged to allow time for other users of the computer sets. The control group was taught as before.

(3) The post-treatment phase: At the end of the third week the SLEAT was administered on both experimental and control groups. The results of the test was collected and collated ready for analysis. The t-test statistic was used to test the hypotheses formulated at 0.05 level of significance.

\section{Results}

Base on the analysis of data from the study, the following results were presented according to the hypotheses formulated.

\section{Hypothesis 1}

There is no significant difference between the mean achievement scores of students in the experimental and control groups. The test of this hypothesis is presented in table 1 .

Table 1: t-test of Mean Achievement Scores of Students in the Experimental and Control Groups.

\begin{tabular}{llccccc}
\hline Variables & $\mathbf{N}$ & $\mathbf{d f}$ & $\overline{\mathbf{X}}$ & SD & t-cal & t-crit \\
\hline Experimental & 30 & 72 & 66.93 & 12.727 & & \\
& & & & & 7.22 & 1.99 \\
$\begin{array}{l}\text { Control Grp } \\
\text { Total }\end{array}$ & 44 & $\cdot$ & 53.23 & 10.541 & & \\
\hline
\end{tabular}

From table 1 the mean achievement score of the experimental group is greater than that of the control group. Also the t-calculated is greater than the table value. This implies that the null hypothesis of no significant difference is rejected. This means that there is a significant difference in favour of the experimental group.

\section{Hypothesis 2:}

There is no significant difference between the mean achievement scores of male and female students in the experimental group. The test of this hypothesis is presented in table 2

Table 2: t-test of Male and Female Students Exposed in the Experimental Group.

\begin{tabular}{llccccc}
\hline Variable & $\mathbf{N}$ & Df & $\overline{\mathbf{X}}$ & SD & t-cal & t-crit \\
\hline Male & 16 & 28 & 43.31 & 11.434 & 0.20 & 1.99 \\
$\begin{array}{l}\text { Female } \\
\text { Total }\end{array}$ & 14 & & 41.68 & 12.334 & & \\
\hline
\end{tabular}

$\mathrm{P} \leq 0.05$

From table 2 the mean difference between male and female students' achievement scores is (43.3141.68)=1.63 which is very small. The calculated $t$-value of 0.20 is less than the table value of 1.99. This indicates that the null hypothesis of no significance difference is accepted. This implies that there is no significant mean achievement scores between male and female students in the experimental group. 


\section{Discussion}

The results showed that students exposed to MATLAB as an autonomous learning strategy achieved substantially higher than those exposed to conventional method of teaching. This finding agrees with those of Costner (2002) and Yaushua (2004) although they used different approaches as explained above. This is because MATLAB has the potential of creating in students the power of enquiry, interaction with a variety of models of mathematics concepts as well as improve their heuristic problem solving skills. It could have the power of encouraging investigative skills and thereby paving the way for mathematical activities that could lead to a higher cognitive level of achievement.

Furthermore, the result also showed no significant difference in the mean achievement scores between the male and female participants exposed to MATLAB as an autonomous learner strategy. This finding does agree with those of Yaushuya (2004) who found no significant difference in some strategy. This finding does not agree with those of Lauchance and Mazzocco (2006), Blosfield etal (2009) who found that male out achieved female. Despite the differences, it can easily be deduced that autonomous learning strategy through the use of computers is gender friendly and involves student handson and minds- on more than the conventional method. It is could therefore, be observed that learner autonomy using MATLAB has the potential of increasing students' understanding of mathematics concepts that results to improved achievement.

\section{Recommendations}

Based on the results of this study, the following recommendations were made:

1. Since technologies have come to stay with us, mathematics educators are encouraged to use them in their mathematics classroom.

2. Learners' autonomy should be encouraged among the students. This is because technology is within the reach of every undergraduate student today

3. Female students should be made to realize that the learning of mathematics is not exclusive of any gendre.

4. School administrators should have the will to made available adequate soft and hard wares, which will promote the teaching and learning of higher mathematics.

\section{Conclusion}

Matrix laboratory (MATLAB) as one of the technological innovation aimed at improving the teaching and learning of mathematics was the focus of this study. This was targed learners' autonomy since it gives the learner the opportunity of studying mathematics with a very minimal assistance. The study showed its efficacy as students improved on the mathematics concept taught during the period of the reach. Base on this, recommendations were therefore made

\section{References}

[1] Armstrong, S. M. (1997). A Multivariate analysis of the dynamics of factors of social context curriculum and classroom process to achievement in calculus at he community college. Dissertation Abstract international 58(03)783.

[2] Blossfield. H.P, B. W. Hannover, B. Lenzen, D. Mueller-Boeling D. \& Prenzel, M. (2009). Gender differences in the Educational system Annual report -2009 Wiesbaden Vs Veriafurer Soziaimissenshalten

[3] Campell, C. P (1994) . A study of the effects of using computers algebra system in college algebra. Dissertation Abstract international 56(9), 3489

[4] Conster, B. G. (2202). The effects on students' achievement and attitudes of incorporating a computer algebra system into a remedial college mathematics course. Dissertation Abstract international 63 (07), 2483

[5] Federal Republic of Nigeria (FRN, 2004). National Policy on Education (4" edition Lagos NERDC Press

[6] Freeman. J. (2003) Gender differences in gifted achievement in Britain and the US. Gifted quarterly 47,202-211

[7] Gusen, J. 2001). The Information Communication Technology. A challenge for the classroom teachers. A paper presented at the maiden National conference of education staff union (COEASU) Federal college of education Pankshin, May 2 to 5

[8] Grouve, D. \& Zand, H. (2000). Computer ad undergraduate mathematics setting the scene. Computer and Education 35. 95-12)

[9] Kulik, C. C., \& Kulik, S. A. (1991). Effectiveness of computer based instruction. An updated analysis. Computer and Human Behaviour, 7 (1) 75-94.

[10] Lachane, J. A.\& Mazzocco, M.M. (2006). A Longitudinal analysis of sex differences in mathematics and partial skills in primary school aged children. Learning and_Individual Differences 16(3), 195-216

[11] Mark, L Barbara, S Rens, V. S Petra, W. Monica, F \& Christiana, E (2012). Life-long learning as a goal. and self regulation in school result in well Prepared pupils? Journal of learning and instruction 22-27-38.

Do autonomy

[12] Mercer, N. (2000). Hands and Mind How to use language to think London Routiege

[13] Ojo, O. J. (2003). Relative effects of self regulatory and cooperative learning strategies on learning outcomes in mathematics. Unpublished Ph.D thesis, University of Ibadan

[14] Piaset, Jean. (1972). The child's conception of the world. Iowa, N. J Littlefield. Adams \& Co.

[15] Shaughnessy, M. F. (1993). Scores on the 16 personality factor test and success in college calculus 1. Report-Research (143), New Mexico: US

[16] Vygotsky, C. S. (1978). Mind on society; Development of Higher psychological processes’ Harvard University Press

[17] Wertson, J (1985). Vyotsky and the Social Formation of mind. Cambridge. M. A. Harrad University press

[18] Yushau, B. (2004). The predictors of success of computer aided learning of pre-calculus algebra Ph.D Thesis University of south Africa

[19] Yvan. D. (2012). Teaching approaches encouraging autonomous learning. Educations 2(4); 96100

[20] Yvette, S (2007). Experiencing mathematics classes, Ability grouping gender and the selective development of participative identities. International Journal of Education Research 46. 8-9. 